\title{
La fotografía como documento informativo en las webs de los ministerios españoles. Acceso, visibilidad, funcionalidad y políticas de uso
}

\author{
Antonia Salvador-Benítez*, Juan Miguel Sánchez-Vigil* \\ *Universidad Complutense de Madrid, Facultad de Ciencias de la Documentación \\ Correos-e: asalvador@ccinf.ucm.es; jmvigil@ccinf.ucm.es
}

Recibido: 15-04-2015; 2a versión: 16-07-2015; Aceptado: 15-09-2015.

Cómo citar este artículo/Citation: Salvador-Benítez, A.; Sánchez-Vigil, J.M. (2016). La fotografía como documento informativo en las webs de los ministerios españoles. Acceso, visibilidad, funcionalidad y políticas de uso. Revista Española de Documentación Científica, 39(2): e134. doi: http://dx.doi.org/10.3989/redc.2016.2.1295

Resumen: La información pública constituye un corpus documental de excepcional interés. Sus valores han obligado a regular tanto el uso como la reutilización mediante leyes específicas, con el fin de ponerla a disposición de empresas, instituciones, investigadores y ciudadanos en general. Una parte de dicha información la constituyen los documentos fotográficos generados y difundidos a través de organismos públicos, sobre los que apenas se han realizado estudios. Se pretende con esta investigación conocer el uso de la fotografía como documento en las páginas webs de los ministerios españoles, analizando aspectos concretos como el acceso, la visibilidad, la funcionalidad, la documentación y los derechos. De la investigación resulta que los usuarios tienen a su disposición cerca de 30.000 fotografías en la web, y se concluye la necesidad de crear un banco de imágenes común, recuperar las fotografías dispersas, normalizar la funcionalidad y terminología, así como establecer criterios comunes para la documentación de los originales.

Palabras clave: Acceso; administración pública; documentación informativa; documentación fotográfica; fotografía; funcionalidad; ministerios; políticas de uso; visibilidad; webs.

Photographs on Spanish Ministries websites as informative documents. Access, visibility, functionality and usage policies

\begin{abstract}
Public information constitutes a documentary corpus of exceptional interest. Its value has made it necessary to regulate both its use as well as its reutilization by means of specific laws, with the purpose of placing this information at the disposal of companies, institutions, researchers and citizens in general. An important part of this information consists of the photographic documents produced and distributed by public bodies, about which very few studies have been carried out. The purpose of this investigation is to learn more about the use of photographs as documents that are found on the websites of Spanish Ministries, by analyzing specific aspects such as the access to them, their visibility, functionality, documentation and rights. This investigation finds that users have at their disposal close to 30,000 photographs available on the web and concludes by recommending the creation of a common image bank to gather the dispersed photographs and normalize both functionality and terminology, as well as establishing common criteria for documenting the originals.
\end{abstract}

Keywords: Access; public administration; informative documentation; photographic documentation; photography; functionality; ministries; policies for use; visibility; websites.

Copyright: () 2016 CSIC. Este es un artículo de acceso abierto distribuido bajo los términos de la licencia Creative Commons Attribution-Non Commercial (by-nc) Spain 3.0. 


\section{INTRODUCCIÓN}

Señala Codina (2006) que las empresas vinculadas al mundo de la comunicación, las universidades, así como diversos organismos de la Administración pública constituyen los principales agentes en lo que a publicación de contenidos digitales de calidad se refiere. Las páginas web de los ministerios españoles son, en consecuencia, un referente informativo, es decir un medio de comunicación de la administración pública. La información generada es de gran interés para empresas, particulares e investigadores, y entre ella se encuentra la documentación fotográfica. Esto justifica la necesidad de revisar y evaluar los sitios web de dichas instituciones y las políticas de producción de contenidos digitales, un ámbito que se corresponde con las competencias del nuevo sector documental de la gestión de contenidos.

El impacto de los contenidos digitales en la sociedad resulta aún más notorio cuando la Agenda Digital para España, publicada en 2013 por el Ministerio de Hacienda y Administraciones Públicas, incluye en su objetivo 2.3 "Impulsar la producción y distribución a través de Internet de contenidos digitales que sirvan para promover no sólo las herramientas y plataformas para la producción de contenidos en todos los sectores, sino también la creación de contenidos digitales educativos, culturales y de entretenimiento, en todos los formatos".

La presentación de la documentación fotográfica se realiza en la web bien como unidades documentales o bien en galerías, definidas solo desde el punto de vista periodístico como "Sucesos noticiosos mediante conjuntos de imágenes" (López, 2010), si bien entendemos que esta visión limitada a la prensa puede ampliarse a otras áreas, por lo que proponemos la siguiente definición de las galerías: "Conjuntos de fotografías de carácter informativo y/o documental cuyos contenidos se relacionan con uno o varios temas, dispuestos en orden secuencial de acuerdo a la metodología de quien los elabora".

Un aspecto fundamental a tener en cuenta es la reutilización de la información del sector público, regulada por la Ley 37/2007 que pretende fomentar el uso de la información pública por parte de las empresas y ciudadanos con el objetivo de generar negocio y favorecer el crecimiento económico en el ámbito de la Unión Europea. En este marco se aprobó en 2009 el Proyecto Aporta para impulsar el mercado de la reutilización de la información pública y se puso en marcha el Catálogo de datos de la Información Pública, constituyendo el primer acceso único de España a las fuentes de datos disponibles del sector público estatal.
Según el texto de la Ley, se entiende por reutilización de la información del sector público: "El uso de los documentos que obran en poder de las administraciones y órganos del sector público, por personas físicas o jurídicas, con fines comerciales o no comerciales, siempre que dicho uso no constituya una actividad administrativa pública" (Ley, 2007). Por consiguiente, las fotografías con propiedad intelectual de los ministerios son susceptibles de reproducción, lo que significa que los documentalistas en su función, y/o los interesados (estudiosos, profesionales, investigadores, etc.) disponen de un extraordinario banco de imágenes, con las limitaciones que se indican en la propia Ley (Artículo 3.3).

La consideración de información pública de las fotografías difundidas en las webs de los ministerios, siempre que la propiedad intelectual corresponda a estos, como se ha indicado, viene amparada por la Ley de Transparencia, Acceso a la información y Buen Gobierno de 2013, al presentar la información como "Los contenidos o documentos, cualquiera que sea su formato o soporte, que obren en poder de alguno de los sujetos incluidos en el ámbito de aplicación de este título y que hayan sido elaborados o adquiridos en el ejercicio de sus funciones" (Ley, 2013).

La información en la administración pública española se ha investigado desde la reutilización (Arquero y otros, 2011) y en relación con la fotografía se han realizado trabajos sobre el patrimonio en instituciones públicas españolas (Sánchez, 2011). Sobre metodología y buenas prácticas para la evaluación de la calidad de fuentes y recursos digitales, los trabajos de Codina (2000, 2006), Ayuso y Martínez (2006) constituyen la principal referencia. Son de interés los indicadores para la evaluación de la calidad en los cibermedios (Rodríguez y otros, 2012) y los establecidos para el estudio de la foto en las galerías de la prensa digital (López, 2010). Así mismo, en lo que respecta a recursos son de referencia los trabajos sobre prensa digital (Sánchez y otros, 2007; Caminos y otros, 2006; Yuste y otros, 2006). Más allá de este campo se produce un considerable vacío, por lo que creemos fundamental la investigación sobre el tema.

Con este planteamiento introductorio, considerando la presencia de la fotografía y su interés informativo-documental, es objeto de esta investigación el análisis de la misma como documento informativo en las webs de los ministerios, con el objetivo específico de conocer el acceso, visibilidad, configuración, funcionalidad, documentación y los aspectos relacionados con las políticas de uso y los derechos. 


\section{METODOLOGÍA}

La investigación se ha aplicado a las páginas web de los doce ministerios españoles actuales, que citaremos en adelante con las siglas que se indican: 1. Asuntos Exteriores y Cooperación (AEC); 2. Agricultura, Alimentación y Medio Ambiente (AMA); 3. Defensa (DEF); 4. Educación, Cultura y Deportes (ECD); 5. Economía y Competitividad (ECO); 6. Empleo y Seguridad Social (EMP); 7. Fomento (FOM); 8. Hacienda (HAC); 9. Industria, Energía y Turismo (IET); 10. Interior (INT), 11. Justicia (JUS); 12. Sanidad, Servicios Sociales e Igualdad (SAN).

La metodología toma como referencia los trabajos de Luis Codina $(2000,2006)$ y está basada en el desarrollo y definición de una serie de parámetros e indicadores específicos para el análisis que se pretende realizar, además de la cuantificación de las fotografías. El estudio contempla cinco indicadores generales referidos a secciones con contenido fotográfico y galerías de imágenes -Acceso, Configuración, Funcionalidad, Documentación y Derechos o políticas de uso- que reúnen un total de 15 parámetros de los que se ha obtenido información para elaborar los resultados (tabla I).

Para analizar el primero de los indicadores -Acceso a las galerías fotográficas- se han establecido tres parámetros que aportamos como estándares: 1. Acceso directo desde el menú principal, 2. Acceso directo desde la página de inicio, y 3. Acceso indirecto desde las secciones. Se analiza además el sistema de etiquetas, es decir la terminología utilizada en cada caso para la denominación de las galerías con contenido fotográfico, analizando su claridad y consistencia. Para evaluar la visibilidad del portal web (número de citas) se ha utilizado la opción correspondiente en el motor de búsqueda de Google para cada ministerio.

El análisis de Configuración y Funcionalidad sigue los indicadores de López (2010), completados con nuevas propuestas específicas diseñadas ad hoc en este estudio para Documentación y Derechos. Para la evaluación de la Configuración se ha contemplado el volumen de imágenes disponibles en la web y la organización de los contenidos fotográficos, es decir si se establece la distinción entre vídeos, fotos, multimedia, etc. En lo que respecta a la Funcionalidad se ha considerado si se incorpora un buscador, la disponibilidad de fotos de archivo, la posibilidad de descarga y el control de la visualización por el usuario.

La evaluación del indicador correspondiente a Documentación se ha basado en cuatro parámetros: el pie de foto o texto explicativo de la imagen, información sobre autoría, presencia de descriptores o palabras clave, y procedencia. Finalmente, para la evaluación de los Derechos y/o políticas de uso, se analiza en cada caso la posible reutilización y si se especifican derechos o políticas aplicables a las fotografías.

Tabla I. Parámetros e indicadores para el análisis de las fotografías en las webs de los ministerios

\begin{tabular}{|c|c|c|}
\hline INDICADORES & PARÁMETROS & Puntuación \\
\hline \multirow{3}{*}{ 1. ACCESO Y Visibilidad } & A. Desde menú principal, inicio u otras secciones & $0-3$ \\
\hline & B. Etiquetas de acceso & $0-2$ \\
\hline & c. Visibilidad de la web & $0-3$ \\
\hline \multirow{2}{*}{ 2. Configuración } & D. Volumen de imágenes disponibles en la web & $0-1$ \\
\hline & E. Distinción entre vídeos, fotos, multimedia, etc. & $0-1$ \\
\hline \multirow{4}{*}{ 3. FUNCIONALIDAD } & F. Disponibilidad de buscador & $0-3$ \\
\hline & G. Fotografías de archivo & $0-3$ \\
\hline & H. Descarga de las fotografías & $0-1$ \\
\hline & I. Control de la visualización por el usuario & $0-3$ \\
\hline \multirow{4}{*}{ 4. DOCUMENTACIÓN } & J. Pies de foto o textos explicativos & $0-1$ \\
\hline & K. Autoría de las fotografías & $0-1$ \\
\hline & L. Descriptores o palabras clave & $0-1$ \\
\hline & M. Procedencia de las fotos & $0-1$ \\
\hline \multirow{2}{*}{ 5. DeRECHOS } & N. Reutilización las imágenes & $0-1$ \\
\hline & o. Derechos y/o políticas de uso & $0-1$ \\
\hline & TOTAL & 26 \\
\hline
\end{tabular}

Fuente: Elaboración propia. 
Para la evaluación cualitativa de cada uno de los indicadores y parámetros se han establecido escalas de puntuación de tipo binario 0-1 ( $\mathrm{Si} / \mathrm{No}$ ); y escalas 0-2 y 0-3, para matizar entre un mal cumplimiento (0); cumplimiento suficiente pero con limitaciones (1); cumplimiento notable (2), y cumplimiento excelente (3). La suma de los valores ideales ( 26 puntos) comparada con la suma de los valores reales obtenidos por cada uno de los ministerios, ha permitido obtener los resultados.

Para contextualizar, se ha contactado con los responsables de las webs de los ministerios al objeto de tener información general sobre la disponibilidad de los bancos de imágenes o fototecas en cada centro, así como sobre su variedad. La respuesta ha sido muy diversa y en ocasiones nula, incluso sin posibilidad de cuantificar, como en el caso del ministerio de ECD por las numerosas instituciones con fondos (Subdirección General de Coordinación Bibliotecaria, Gerencia de Infraestructuras y Equipamientos, Instituto de Cinematografía y de las Artes Audiovisuales, o el Instituto Nacional de Tecnologías Educativas y de Formación del Profesorado.

\section{RESULTADOS}

Se han analizado las webs de todos los ministerios, si bien en el caso de HAC y de ECD los resultados son parciales, ya que sus webs carecen de galerías de imágenes y/o fototeca, y por tanto los elementos de análisis quedan limitados. A continuación se presentan los resultados del análisis y las puntuaciones obtenidas por cada ministerio en los cinco indicadores señalados en la metodología.

\subsection{Acceso y visibilidad de las galerías fotografías}

De los tres criterios específicos establecidos como estándares -acceso directo desde el menú principal (barra superior o márgenes de la página); acceso directo desde la página de inicio (mediante iconos o enlaces), y acceso indirecto (desde las secciones o sumarios locales)- cabe señalar que ninguno de los ministerios tiene acceso directo desde el menú principal, solo cuatro lo incluyen en la página de inicio (a través de un enlace de texto o icono), siendo la práctica común en todos los casos el acceso indirecto a partir de la sección "Prensa" o "Sala de prensa".

Sobre la denominación de las secciones con contenidos fotográficos, se ha observado que no existe una terminología común en los ministerios para nombrar la sección específica con fotografías, ya que se emplean etiquetas diferentes: Galería de imágenes (AEC, AMA), Galería de Fotos (JUS), Fotos (JUS), Fototeca (DEF, IET), Imágenes (EMP, FOMO, INT), Galería Multimedia (ECO), e incluso el genérico Fotografías (SAN).
En cuanto a la visibilidad del portal web, el ministerio con mayor número de citas es ECD (4.480), seguido por AMA (1.970), IET (1.370) y EMP (1.190). En un segundo nivel, por debajo del millar, se encuentran AEC (856), HAC (770) y FOM (687), seguidos de INT (586), DEF (543) y JUS (360). La herramienta de Google empleada no arroja resultados para Sanidad y Economía. La escala de valoración se ha establecido por comparación entre los distintos ministerios, siendo 0 ninguna cita, 1 menos de 500,2 más de 500 y 3 más de 1.000 citas. La visibilidad de las galerías, teniendo en cuenta el modo de acceso, es nula en dos casos (ECD y HAC), y notable en cuatro casos (AEC, INT, JUS y SAN). En los seis ministerios restantes la visibilidad es suficiente con limitaciones, ya que no se accede de forma directa sino a través de otras secciones (Tabla II).

\subsection{Configuración}

Se contemplan en este apartado el volumen de imágenes disponibles en la web y la distinción entre los tipos de documentos que se presentan para su uso. En todos los portales se establece una distinción clara por tipo, con tres modelos concretos: "Vídeos", "Fotos" y "Multimedia", y en algunos casos también se especifica "Noticias".

Ningún ministerio ofrece datos cuantitativos sobre las imágenes disponibles en la web, por lo que las cifras reflejadas en las tablas son resultado del análisis y cuantificación de las herramientas de consulta de cada uno de ellos, aportando una cantidad estimativa de 28.700 fotografías. El conjunto disponible en los portales varía considerablemente, desde las 200 fotos en AEC a las más de 15.000 de INT. A los ministerios de ECD y de HAC se les adjudica un número mínimo para valorar las fotos de carácter ilustrativo, equivalente a 50 unidades, ya que no disponen de galería o fototeca (Figura 1).

\subsection{Funcionalidad}

De los diez ministerios que disponen de galerías de imágenes o fototeca en su web, siete incorporan un buscador con diferentes opciones. Los más sencillos ofrecen filtros por fecha (dd/mm/aa) como es el caso de DEF, ECO, EMP, IET y JUS, además de la búsqueda por fecha (año-mes) incorporan un campo de texto libre. El buscador del ministerio de AMA ofrece opciones de búsqueda simple (campo texto libre) y avanzada con filtros por fecha de publicación ( $\mathrm{dd} / \mathrm{mm} / \mathrm{aa}$ ) y palabra clave (uno o más términos). La herramienta de búsqueda más completa la ofrece FOM que incorpora filtros por Área de actividad (listado predefinido), Ámbito geográfico, Fecha (Desde-Hasta) y Tipo de recurso (Noticias, Imágenes, Recursos audiovisuales). Los ministerios de AEC, INT y SAN no tienen buscador de imágenes, si bien INT ofrece opciones de búsqueda de "Documentos", "Audio" y "Vídeo", pero no de fotos. 
Tabla II. Modo de acceso a las galerías/fototecas, visibilidad del portal web y de las galerías*

\begin{tabular}{|c|c|c|c|c|}
\hline & $\begin{array}{l}\text { ACCESO DIRECTO } \\
\text { INICIO }\end{array}$ & $\begin{array}{l}\text { ACCESO INDIRECTO } \\
\text { (DESDE OTRAS SECCIONES) }\end{array}$ & $\begin{array}{c}\text { VISIBILIDAD } \\
\text { PORTAL WeB } \\
\text { no citas }^{\circ}\end{array}$ & $\begin{array}{l}\text { VISIBILIDAD } \\
\text { GALERÍAS }\end{array}$ \\
\hline AEC & 1 & 1 (Sala de Prensa) & 2 & 2 \\
\hline AMA & 0 & 1 (Sala de Prensa) & 3 & 1 \\
\hline DEF & 0 & 1 (Prensa) & 2 & 1 \\
\hline ECD & 0 & 0 (No tiene) & 3 & 0 \\
\hline ECO & 0 & 1 (Prensa) & 0 & 1 \\
\hline EMP & 0 & 1 (Actualidad, Sala de Prensa) & 3 & 1 \\
\hline FOM & 0 & 1 (Sala de prensa) & 2 & 1 \\
\hline HAC & 0 & 0 (No tiene) & 2 & 0 \\
\hline IET & 0 & 1 (El Ministerio. Gab. de Prensa) & 3 & 1 \\
\hline INT & 1 & 1 (Prensa) & 2 & 2 \\
\hline JUS & 1 & 1 (Noticias del Ministerio) & 1 & 2 \\
\hline SAN & 1 & 1 (Gabinete de Prensa) & 0 & 2 \\
\hline
\end{tabular}

Fuente: Elaboración propia*

*Modo de Acceso (directo/indirecto): Valores: 0 (No), 1 (Si)

Visibilidad portal web: Valores: 0 (Ninguna cita), 1(-500 citas), 2 (+500 citas), 3 (+ 1.000 citas)

Visibilidad galerías: Valores: 0 (Nula), 1(Suficiente con limitaciones), 2 (Notable)

Figura 1. Comparativa del número de fotografías en las webs de los ministerios

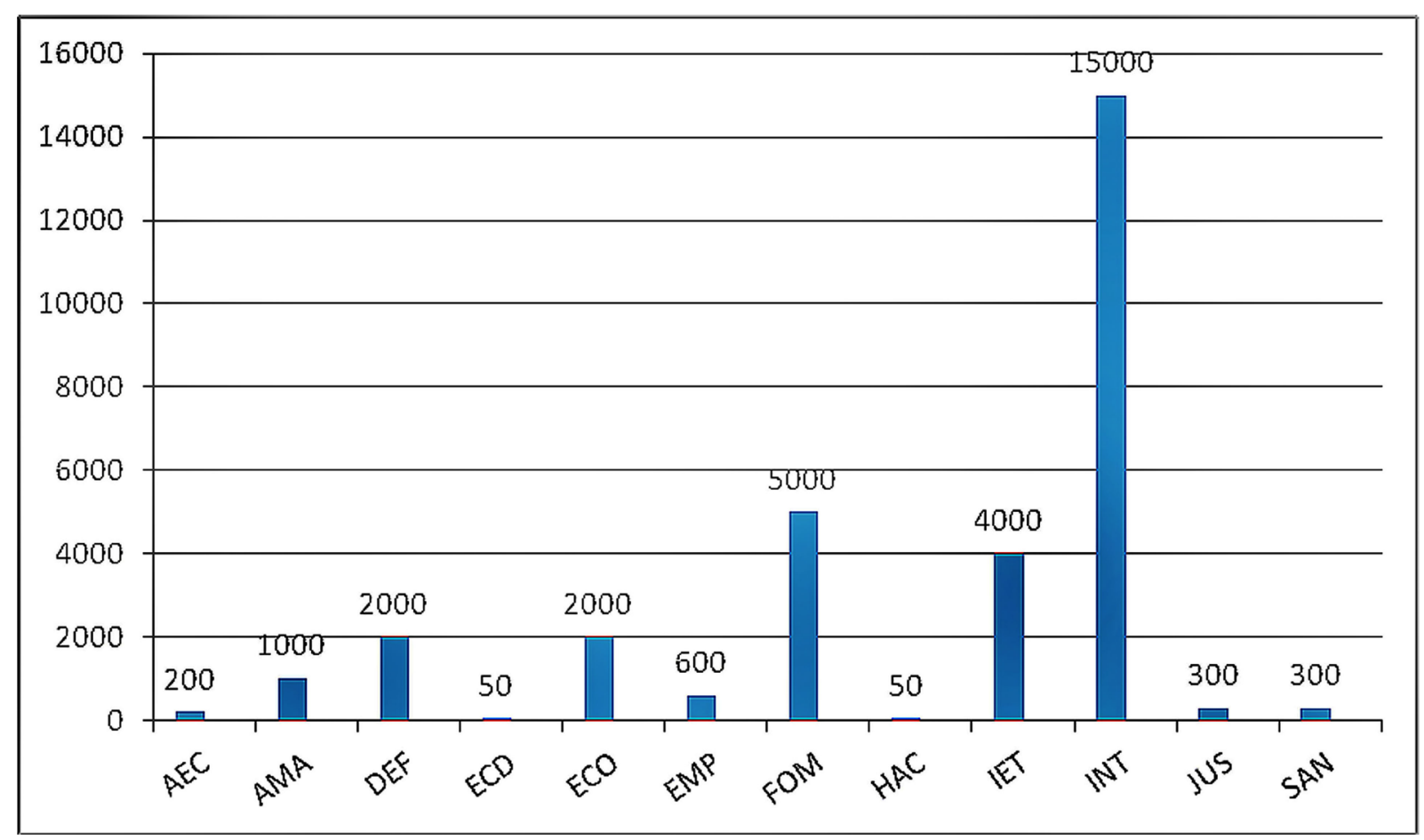


Además de fotografías de actualidad, todos los ministerios disponen de imágenes de archivo en la web, excepto ECD y HAC que carecen de galerías (Tabla III). Las fechas extremas son variables, siendo los de DEF y FOM los que ofrecen una mayor cobertura (2004-2015), seguidos de IET (2006-2015), EMP (2008-2015), AMA, INT y SAN (2011-2015) y ECO (2012-2015). Los ministerios que ofrecen imágenes de archivo con menor cobertura son AEC y JUS (2014-2015). La valoración de este indicador ha seguido una escala de 0 -3 en función de la cobertura, siendo 0 (Ninguna); 1 ( 2 a 5 años); 2 (6 a 10 años) y 3 (más de 10 años).

La descarga puede realizarse en alta calidad en nueve ministerios (ficheros jpg, tiff). ECD, HAC y ECO, facilitan la copia de la imagen pero no permiten la descarga. En este apartado es modélico AMA con tres opciones: impresión, descarga en jpeg y en pdf. En todos los casos el usuario puede seleccionar el modo de visualización de las imágenes, siendo frecuentes en mosaico y foto a foto (DEF, FOM, IET e INT). Permiten la visualización de las imágenes de modo secuencial (anterior y siguiente) los ministerios de AMA y SAN, y la gama más amplia la ofrecen AEC, ECO y JUS, con opciones en mosaico, secuencial y modo presentación de diapositivas.

\subsection{Documentación}

En todos los casos, las fotografías incorporan la fecha y un pie de foto o texto explicativo. Las imágenes de FOM e IET incluyen además descriptores para la recuperación. En el caso de AEC se indica la autoría y la procedencia de las imágenes. Una característica destacada la aporta FOM, que junto a cada fotografía ofrece un enlace a los documentos y notas de prensa relacionadas, así como a las imágenes asociadas que forman parte del mismo reportaje. El tratamiento documental, es decir la adjudicación de descriptores, ampliaría considerablemente las posibilidades de recuperación y por tanto de reutilización de las imágenes.

\subsection{Derechos y políticas de uso}

Solo en cuatro casos se incluye en las galerías o fototecas información acerca de los derechos y políticas de uso de las imágenes. Concretamente DEF, ECO y SAN permiten la reutilización citando la fuente, y en el caso de IET están bajo licencia Creative Commons. Para los demás la única referencia es a la información que consta en el Aviso legal en cada uno de los Portales, siendo SAN el único que incluye en la sección gráfica un enlace a dicha información.

Tabla III. Disponibilidad de fotos de archivo en las webs de los ministerios

\begin{tabular}{|c|c|c|c|c|c|c|c|c|c|c|}
\hline AÑo & AEC & AMA & DEF & ECO & EMP & FOM & IET & INT & JUS & SAN \\
\hline \multicolumn{11}{|l|}{2004} \\
\hline \multicolumn{11}{|l|}{2005} \\
\hline \multicolumn{11}{|l|}{2006} \\
\hline \multicolumn{11}{|l|}{2007} \\
\hline \multicolumn{11}{|l|}{2008} \\
\hline \multicolumn{11}{|l|}{2009} \\
\hline \multicolumn{11}{|l|}{2010} \\
\hline \multicolumn{11}{|l|}{2011} \\
\hline \multicolumn{11}{|l|}{2012} \\
\hline \multicolumn{11}{|l|}{2013} \\
\hline \multicolumn{11}{|l|}{2014} \\
\hline 2015 & & & & & & & & & & \\
\hline
\end{tabular}

Fuente: Elaboración propia*

* Los ministerios de Hacienda y de Educación, Cultura y Deporte carecen de galerías en la web. 
Las condiciones generales incluidas en el Aviso legal señalan que la información en los Portales de los ministerios puede ser utilizada de forma total o parcial siempre que se cite la fuente, se solicite autorización y el contenido de los documentos permanezca íntegro, salvo los contenidos con derechos de propiedad intelectual o industrial por parte de terceros, quedando autorizada su reproducción total o parcial, modificación, distribución y comunicación pública para usos comerciales y no comerciales. El Portal de FOM incluye un Aviso legal escueto y sin referencias a la reutilización de contenidos y AEC sólo hace mención a la protección de datos de carácter personal.

En cualquier caso se trata de políticas de uso genéricas y con escasa concreción en la reutilización de imágenes. El Aviso legal en los casos de DEF, INT, JUS y SAN señala que las imágenes están protegidas por los correspondientes derechos contenidos en el servidor de JUS. La licencia de uso de cualquier contenido del Portal otorgada al usuario se limita a la descarga y el uso privado, siempre que dichos contenidos permanezcan íntegros. Remiten a las condiciones que permiten la reutilización de los documentos sometidos a ellas para fines comerciales y no comerciales.
La reutilización autorizada incluye, a modo ilustrativo, actividades como la copia, difusión, modificación, adaptación, extracción, reordenación y combinación de la información. Esta autorización conlleva la cesión gratuita y no exclusiva de los derechos de propiedad intelectual, así como la realización de actividades de reproducción, distribución, comunicación pública o transformación, necesarias para desarrollar la reutilización autorizada, en cualquier modalidad y bajo cualquier formato, para todo el mundo y por el plazo máximo permitido por la Ley.

\subsection{Valoración global}

De acuerdo a los valores prefijados se realiza el análisis final comparativo de cada uno de los aspectos tratados. De los doce ministerios evaluados, aprueban IET (17/26), DEF, EMP y FOM (16/26) seguidos de AEC (14/26) y JUS (13/26). A falta de pocas décimas no alcanzan el aprobado ECO y AMA $(12 / 26)$ e INT $(11 / 26)$. Los resultados más bajos corresponden a SAN (10/26), ECD (3/26) y HAC (2/26) (Tabla IV).

Conviene señalar que algunos ministerios presentan soluciones destacables en los parámetros e indicadores analizados. Así, en cuanto a Acceso

Tabla IV. Puntuación total de los indicadores

\begin{tabular}{|c|c|c|c|c|c|c|c|}
\hline & $\begin{array}{c}\text { A } \\
(0-8)\end{array}$ & $\begin{array}{c}\text { B } \\
(0-2)\end{array}$ & $\begin{array}{c}\text { C } \\
(0-10)\end{array}$ & $\begin{array}{c}\text { D } \\
(0-4)\end{array}$ & $\begin{array}{c}\mathbf{E} \\
(0-2)\end{array}$ & $\begin{array}{l}\text { TOtAL } \\
(0-26)\end{array}$ & $\begin{array}{l}\text { NOtA } \\
(0-10)\end{array}$ \\
\hline AEC & 5 & 1 & 5 & 3 & 0 & 14 & 5.3 \\
\hline AMA & 5 & 1 & 5 & 1 & 0 & 12 & 4.6 \\
\hline DEF & 4 & 1 & 8 & 1 & 2 & 16 & 6.0 \\
\hline ECD & 3 & 0 & 0 & 0 & 0 & 03 & 1.1 \\
\hline ECO & 2 & 1 & 6 & 1 & 2 & 12 & 4.6 \\
\hline EMP & 5 & 1 & 8 & 1 & 1 & 16 & 6.0 \\
\hline FOM & 4 & 1 & 9 & 2 & 0 & 16 & 6.0 \\
\hline $\mathrm{HAC}$ & 2 & 0 & 0 & 0 & 0 & 02 & 0.7 \\
\hline IET & 5 & 1 & 7 & 2 & 2 & 17 & 6.5 \\
\hline INT & 5 & 1 & 4 & 1 & 0 & 11 & 4.2 \\
\hline JUS & 4 & 1 & 7 & 1 & 0 & 13 & 5.0 \\
\hline SAN & 3 & 1 & 3 & 1 & 2 & 10 & 3.8 \\
\hline & & & \multicolumn{5}{|c|}{$\begin{array}{l}\text { A. Acceso y Visibilidad; } \\
\text { B. Configuración; } \\
\text { C. Funcionalidad; } \\
\text { D. Documentación; } \\
\text { E. Derechos }\end{array}$} \\
\hline
\end{tabular}

Fuente: Elaboración propia 
y visibilidad de las galerías fotográficas, el modelo más acertado es el que ofrecen JUS e INT con un acceso en la página de inicio que permite una clara identificación y localización de las galerías.

En cuanto a la Funcionalidad, es especialmente destacable el modelo de FOM, por presentar la herramienta de búsqueda más completa y disponer, junto con $D E F$, de uno de los archivos de fotografías online con mayor cobertura (2004-2015). Las mejores soluciones de visualización las ofrecen AEC, JUS y ECO, en forma de mosaico, secuencial y presentación de diapositivas.

Como puntos débiles en todos los casos señalaremos los indicadores Documentación y Derechos. Consideramos que estos aspectos deben ser atendidos, especialmente las informaciones referidas a la autoría y procedencia de las fotografías (sólo contempladas por AEC), así como los derechos y políticas que afectan a las imágenes, ya que son determinantes tanto para su adecuada gestión desde los propios ministerios como para el correcto uso de las fotografías por parte de los usuarios del portal

\section{CONCLUSIONES}

La implantación de una cultura de la transparencia impone una modernización de la Administración y el empleo de los medios electrónicos para facilitar el acceso a la información. En el caso que nos ocupa, garantizar el acceso efectivo a los fondos fotográficos supone que en ellos se ha efectuado previamente una correcta y completa labor de inventariado, sistematización y análisis documental de todos y cada uno de los imágenes que conforman el fondo, se ha procedido a su informatización en una base de datos y su integración en un catálogo así como una correcta preservación de todos los documentos que forman parte del archivo. Todo esto implica que la institución tiene una clara conciencia del valor cultural, social e histórico de este patrimonio tanto para la propia institución como para la sociedad en general.

Desde la perspectiva de la transparencia y la reutilización de la información, sería conveniente proporcionar información de forma estructurada y preferentemente a través de un espacio dedicado en la sede electrónica de cada ministerio, sobre las fotografías disponibles, en qué formatos se ofrecen y las condiciones aplicables a su utilización, facilitando la búsqueda y recuperación de las imágenes a través de índices y bases de datos.

En consecuencia, y con el fin de poner en valor la documentación fotográfica de que disponen, serían necesarias dos actuaciones concretas: por una parte la creación de un banco de imágenes o fototeca digital, común para todos los ministerios, en la que se incluyan todas las fotografías tratadas documentalmente (difundidas o no en la web), y por otra la recuperación de las fotos dispersas en los diferentes departamentos de cada ministerio, al objeto de documentarlas e incluirlas en el banco de imágenes. Sería deseable que los departamentos competentes adoptaran medidas de colaboración para la creación y mantenimiento de dicho banco de imágenes correspondiente al menos a los Ministerios que permita acceder desde un único punto a las imágenes disponibles. Tal y como se indica en la valoración de los resultados, algunas de las actuaciones de los ministerios son modélicas y por tanto referentes para su aplicación. Indicamos como ejemplo a Fomento en lo que respecta a la búsqueda y recuperación.

Para mejorar la accesibilidad y visibilidad, este catálogo debería tener un acceso directo en la sede web de cada ministerio, bajo un icono y una denominación común y fácilmente identificable para el usuario. El análisis realizado revela que en ninguno de los ministerios se accede a las galerías o fototecas de forma directa, sino a través de otras secciones (Sala de Prensa o Gabinete de comunicación) y bajo denominaciones e iconos diferentes. Con carácter específico se aporta en este trabajo una definición de galería fotográfica, al objeto de proponer este término para normalizar las etiquetas empleadas en las sedes web de los ministerios.

En cuanto a los derechos, la documentación fotográfica opera en el ámbito de la legislación sobre el derecho de autor y el derecho contractual, por consiguiente, las actividades de acceso, difusión, y en cierta medida, de conservación, se rigen y se ven limitadas por los imperativos legales de los titulares. En este sentido se advierte que las políticas de uso son genéricas y con escasa concreción en cuanto a la reutilización de las imágenes. Entendemos que esta información debería constar de forma expresa en la sección correspondiente de la sede web de cada ministerio de manera que quede clara la posibilidad de explotación de las imágenes, tanto para el propio ministerio como para los medios de comunicación, las empresas, investigadores o ciudadanos en general. Asimismo consideramos que, además del correspondiente aviso legal, se deberían conservar los metadatos sobre la autoría de las imágenes y las condiciones de uso incluidos en las imágenes de manera que estén accesibles de un modo fácil, directo y puedan ser almacenadas y reproducidas por los usuarios vinculándolos por el mero hecho de hacer uso de las imágenes. Con carácter general, las fotografías publicadas en los Portales de 
los ministerios españoles constituyen un excepcional conjunto, compuesto por cerca de treinta mil imágenes que pueden ser reutilizadas por los ciudadanos, investigadores o empresas siempre que se cite la fuente, salvo aquellas sobre las que existan derechos de propiedad intelectual por parte de terceros, quedando autorizada su reproducción, distribución y comunicación pública para usos comerciales y no comerciales. En el caso de IET se indica de forma explícita que las imágenes están bajo licencia Creative Commons.

Por último, sería conveniente facilitar al usuario información y datos de contacto por medios elec-

\section{REFERENCIAS}

Arquero Avilés, R; Valle Gastaminza, F; Ramos Simón, F; Botezan, I; Mendo, C; Sánchez-Jiménez, R; Tejada Artigas, C; Cobo Serrano, S; Sala Jiménez, A. (2011). Reutilización de la información en el sector público español. Revista Española de Documentación Científica, v. 34 (3), pp. 427-446. http:// dx.doi.org/10.3989/redc.2011.3.825

Ayuso García, M. D.; Martínez Navarro, V. (2006). Evaluación de calidad de fuentes y recursos digitales: Guía de buenas prácticas. Anales de Documentación, v. 9, pp. 17-42.

Caminos, J.M; Marín Murillo, F; Armentia Vizuete, J.I. (2006). El uso de la fotografía en los diarios digitales españoles. Comunicación y Sociedad, XIX, 2, p. 9-38.

Codina, L. (2000). Evaluación de recursos digitales en línea: conceptos, indicadores y métodos, $R e-$ vista Española de Documentación Científica, v.23, 1, pp.9-44. http://dx.doi.org/10.3989/redc. 2000. v23.i1.315

Codina, L. (2006). Evaluación de calidad en sitios web: Metodología de proyectos de análisis sectoriales y de realización de auditorías. Barcelona; Universidad Pompeu Fabra. http://eprints.rclis.org/8854/

ESPAÑA. Ministerio de Hacienda y Administraciones Públicas (2013). Agenda Digital para España.

Ley $19 / 2013$ de transparencia, acceso a la información pública y buen gobierno. BOE, 19 de diciembre. Referencia 12887. trónicos, sobre el departamento responsable del archivo gráfico con competencias para la recepción, tramitación y resolución de consultas y solicitudes de imágenes. No consta información sobre el departamento ni la persona responsable a la que dirigirse para solicitar información.

El proyecto, implementación y desarrollo de todas estas tareas, incluida la difusión de las actuaciones y de los resultados, podría y debería llevarse a cabo en el marco de la Ley sobre la reutilización de la información del sector público (2007), y de la Ley de transparencia, acceso a la información y buen Gobierno (2013).

Ley 37/2007 sobre la reutilización de la información del sector público. BOE, 17 de noviembre. Referencia 19814.

López del Ramo, J. (2010). Configuración y contextualización de las galerías fotográficas en los diarios on line. Propuesta de analítica aplicada, El Profesional de la Información, 19 (5), pp. 469-475. http:// eprints.rclis.org/14924/

Rodríguez Martínez, R; Codina, L; Pedraza-Jiménez, R. (2012). Indicadores para la evaluación de la calidad en cibermedios: análisis de la interacción y de la adopción de la Web 2.0, Revista Española de Documentación Científica, v. 35 (1), pp. 61-93. http:// dx.doi.org/10.3989/redc.2012.1.858

Sánchez Vigil, J.M. (2011). Patrimonio fotográfico en instituciones públicas españolas: modelos de uso y reproducción de documentos. El Profesional de la Información, v. 20 (4), pp. 371-377. http://www.elprofesionaldelainformacion.com/contenidos/2011/julio/02.pdf

Sánchez Vigil, J.M; Marcos Recio, J.C.; Villegas Tovar, R. (2007). Los recursos fotográficos en los periódicos digitales. Valores de la foto digital. Ibersid, pp. 211-218.

Villa, I (2008). Particularidades de la fotografía informativa en los medios on-line españoles. Revista latina de comunicación social, v. 63, pp. 303-312.

Yuste Robles, B; Sandoval Martín, T; Franco Álvarez, G. (2006). Uso de la fotografía y la infografía en los periódicos digitales. III Congreso on-line observatorio para la cibersociedad. 